\title{
Climatic Zones of Sri Lanka under Changing Climate
}

\author{
W.R. Edirisinghe, S. Somarathna, B.C.L. Athapattu* \\ The Open University, Nawala, Sri Lanka \\ *bcliy@ou.ac.lk
}

\begin{abstract}
Climate change is the major phenomenon and fundamental human development challenge of the $21^{\text {st }}$ century. It is well known that all climatic regions in Sri Lanka have been experienced with severe climatic changes. As a result, entire flora and fauna including humans are vulnerable to these adverse consequences. In general, it is believed that nations would mitigate the climate change or adapt to the changing environments. For employment of such measures, it is necessary to understand the macro-climatic region and their behavior under the changing global climate. Based on the annual rainfall received, the country is divided mainly into four climatic zones: wet, intermediate, dry and arid. The climate of the country depends largely on the monsoon wind patterns and series of temperature. Therefore, it is necessary to understand the climatic zones and their behavior to identify each climatic zone's minor and major climate changes.
\end{abstract}

The main objective of this study was to study on macro-climatic regions of Sri Lanka under changing climate. Therefore, the present study was carried out on macro-climatic regions of the island to find out the potential variation of temperature and rainfall patterns. Climatic data for the 30 year period were collected from randomly selected metrological stations in each climatic zone and average temperature and rainfall data were analysed using least significant difference (LSD) test.

The results showed that average temperature of the country has increased $0.4^{\circ} \mathrm{C}$ from the year 1869 to 1980 . Kandy (intermediate zone) region shows the higher temperature after the year of 1886 named as colonial era which was prevalent for deforestation and tea cultivation. A significantly increasing trend of temperature and decreasing trend of rainfall could be observed entirely within wet zone, dry zone and intermediate zone in $20^{\text {th }}$ century than 19th century. Findings reveal that the wet zone boundary has squeezed in and dry zone boundary has expanded in recent time. Such boundary movements of the zones are significantly important on reclassification of the dry zone and intermediate zone. Therefore, further studies on climate regions of Sri Lanka under changing climate is needed to examine the relationship between the vegetation cover distribution changes within the boundary of the climatic zones. Hence researchers could identify wet and intermediate zones as a "micro-climatic zones" while dry zone could be identified as a "macro-climatic zone" instead of traditionally generalised term in future.

Keywords: Changing climate, Climatic zones, Macro-climatic region, Zone boundary movement, Colonial era 